\title{
CONGENITAL OSTIAL MEMBRANE OF LEFT CORONARY ARTERY IN TRUNCUS ARTERIOSUS
}

\author{
Jacques A. M. van Son, MD, PhD, Rüdiger Autschbach, MD, and Jörg Hambsch, MD, Leipzig, Germany
}

Myocardial ischemia or myocardial infarction is uncommon among infants and children. It may, however, result from any of several conditions, such as anomalous origin of the left coronary artery (LCA) or right coronary artery from the pulmonary artery, anomalous aortic origin of the coronary arteries, congenital coronary atresia, supravalvular aortic stenosis, calcific coronary sclerosis, homocysteinuria, periarteritis nodosa, fibroelastosis of the coronary arteries, Friedreich ataxia, Hurler syndrome, rubella syndrome, and others. ${ }^{1-4}$ Recently we encountered 2 rare cases of myocardial ischemia and infarction in young patients. Both cases were caused by congenital ostial membrane of the LCA and both were associated with truncus arteriosus.

\section{Clinical summaries}

PATIENT 1. A 5-week-old male neonate was referred with a diagnosis of truncus arteriosus. On arrival at the hospital the patient was in a moribund condition. The patient was in congestive heart failure and had marked cyanosis. The arterial oxygen saturation was $70 \%$. There was severe metabolic acidosis ( $\mathrm{pH}$ 7.08). Echocardiography confirmed the diagnosis of truncus arteriosus; in addition, it showed mild truncal valve regurgitation and a right-sided aortic arch. Electrocardiographically there were signs of severe myocardial ischemia. The neonate died 2 hours after arrival.

Autopsy confirmed the diagnosis of truncus arteriosus type I. The truncal valve was tricuspid. The LCA originated from the left sinus of Valsalva in close proximity to the commissure between the left and right sinuses. A membrane originated from the coronary ostial rim, opposite the commissure, and partially covered the orifice of the LCA. Histologic sections of the ostial membrane clearly demonstrated that the membrane was unrelated to an aortic valve cusp (Fig 1).

From the Herzzentrum, University of Leipzig, Leipzig, Germany.

Received for publication Aug 12, 1999; accepted for publication Aug 17, 1999.

Address for reprints: Jacques A. M. van Son, MD, Herzzentrum, University of Leipzig, Russenstrasse 19, D-04289 Leipzig, Germany.

J Thorac Cardiovasc Surg 1999;118:1132-4

Copyright (C) 1999 by Mosby, Inc.

$0022-5223 / 99 \$ 8.00+0 \quad \mathbf{1 2 / 5 4 / 1 0 2 2 9 2}$

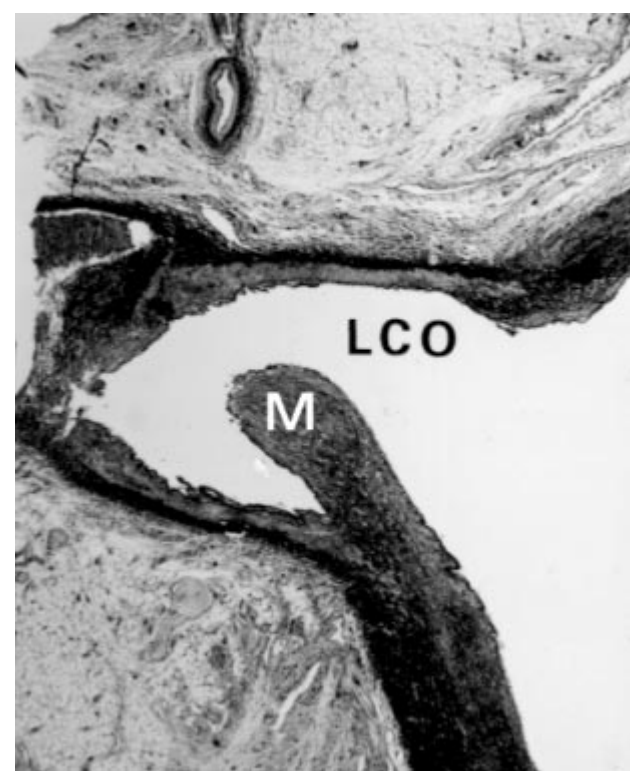

Fig 1. Photomicrograph of transverse section of truncus arteriosus demonstrating membrane $(M)$ that partially covers left coronary orifice $(L C O)$. (Elastin-van Gieson stain; original magnification $\times 20$ ).

PATIENT 2. A 12-year-old male patient was admitted because of recent onset of recurrent angina during exercise. When the patient was 6 months old a truncus arteriosus type I had been repaired. Echocardiography showed an intact repair. There was mild regurgitation of the neoaortic valve. An exercise treadmill test showed a 4-mm ST-segment depression in leads $\mathrm{V}_{4}$ through $\mathrm{V}_{6}$. The coronary angiogram was normal in appearance except that the LCA ostium appeared small. After extensive deliberation because of the severe symptoms in combination with the borderline stenosis of the LCA ostium, an operation was recommended to explore for a possible coronary ostial stenosis. During the operation through a median sternotomy it was seen that the LCA ostium arose from the left sinus of Valsalva in close proximity to the commissure between the left and right sinus- 

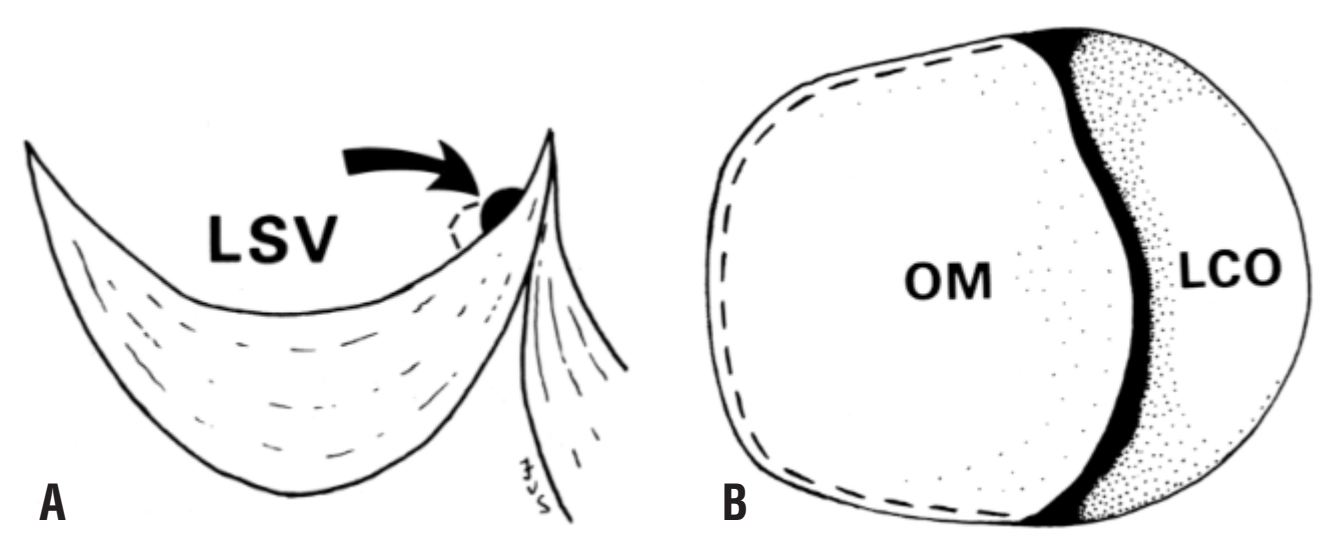

Fig 2. A, In truncus arteriosus rightward migration of left coronary orifice (arrow) results in more tangential origin of LCA and thus increased tendency toward left coronary ostial stenosis. $L S V$, Left sinus of Valsalva. B, Detail showing congenital ostial membrane $(O M)$ that partially covers left coronary orifice $(L C O)$. Resection of membrane (dashed line) results in widely patent left coronary orifice.

es (Fig 2, A). The effective ostium was small because the true ostium was partially covered by a membrane that originated from the coronary ostial rim opposite the commissure (Fig 2, $B)$. Resection of the membrane resulted in a widely patent LCA ostium. The postoperative course was uneventful. Three years after the operation the patient remains free of symptoms; notably, there have been no more episodes of myocardial ischemia during exercise. Echocardiography demonstrated that the regurgitation of the neoaortic valve was not progressive.

Discussion. In truncus arteriosus, as in transposition of the great arteries, great variability exists with respect to site of origin and orifice configuration of the main coronary arteries. Bogers and coworkers ${ }^{5}$ reported a $64 \%$ incidence of such malformations in truncus arteriosus. Despite the variability of coronary arterial ostial position, the LCA orifice is almost always located at the posterior aspect of the truncus and the orifice of the right coronary artery is almost always located in the right anterior and lateral segments of the truncus. ${ }^{5}$ The configuration abnormalities of the coronary arterial ostium previously reported have consisted of a double orifice and a pinpoint orifice. ${ }^{5,6} \mathrm{~A}$ third and hardly recognized form of abnormal configuration of the coronary arterial orifice in truncus arteriosus may be the presence of a congenital ostial membrane. Josa and coworkers $^{7}$ reported 2 cases of congenital ostial membrane of the LCA, 1 in a patient with valvular aortic stenosis and the other in an 8-year-old patient with truncus arteriosus. In contrast with the 12-year-old patient reported on by us, the 8-yearold patient did not have preoperative symptoms of angina or electrocardiographic signs of myocardial ischemia. As in our case both coronary arteries were visualized in the aortic root injection and were interpreted as being normal, although in our case the ostium of the LCA did appear somewhat stenotic. Selective injection of the coronary ostium with a congenital membrane may demonstrate a deceptively normal ostium because the catheter displaces the obstructing ostial membrane.
With respect to the development of coronary arteries, coronary primordia grow from the peritruncal ring into the aorta. ${ }^{8}$ The common denominator of the process and site of ingrowth is not known yet. It is tempting to speculate that the great variability with respect to the site of ingrowth of the coronary arteries into the truncus may result in an increased tendency toward tangential origin of the coronary ostia. From this perspective, congenital membrane of the coronary orifice, pinpoint coronary orifice, double-orifice coronary ostium, and anomalous aortic origin of the LCA (from the right sinus of Valsalva) or the right coronary artery (from the left sinus of Valsalva) may represent different locations on the spectrum of anomalies of origin of the coronary orifice.

Because of the high incidence of malformations of coronary arterial orifice position or configuration and the risk of myocardial ischemia that they carry, preoperative information on the coronary arterial anatomy in as much detail as possible and attention to the coronary orifices during operation may allow further improvements in the surgical treatment of truncus arteriosus. Whereas in cases of anomalous aortic origin of the LCA or right coronary artery we recommend a modified unroofing procedure, ${ }^{4}$ in cases of congenital ostial membrane the membrane is simply resected. In cases of pinpoint coronary orifice the obstructing tissue is resected; when the resection results in a tissue gap between the proximal coronary arterial wall and the orifice wall, the coronary ostium obviously needs to be reconstructed.

\section{REFERENCES}

1. Levin DC, Fellows KE, Abrams HL. Hemodynamically significant primary anomalies of the coronary arteries: angiographic aspects. Circulation 1978;58:25-34.

2. Kimbiris D, Iskandrian AS, Segal BL, Bemis CE. Anomalous aortic origin of coronary arteries. Circulation 1978;58:606-15.

3. Van Son JA, Edwards WD, Danielson GK. Pathology of coronary 
arteries, myocardium, and great arteries in supravalvular aortic stenosis: report of five cases with implications for surgical treatment. J Thorac Cardiovasc Surg 1994;108:121-8.

4. Van Son JA, Mohr FW. Modified unroofing procedure in anomalous aortic origin of left or right coronary artery. Ann Thorac Surg 1997;64:568-9.

5. Bogers AJ, Bartelings MM, Bökenkamp R, Stijnen T, van Suylen RJ, Poelmann RE, et al. Common arterial trunk, uncommon coronary arterial anatomy. J Thorac Cardiovasc Surg 1993;106:1133-7.
6. Chernausek SD, Swan DC, Moller JH, Vlodaver Z, Edwards JE. Clinical pathologic conference. Am Heart J 1976;91:249-54.

7. Josa M, Danielson GK, Weidman WH, Edwards WD. Congenital ostial membrane of left main coronary artery. J Thorac Cardiovasc Surg 1981;81:338-46.

8. Bogers AJ, Gittenberger-de Groot AC, Poelmann RE, Péault BM, Huysmans HA. Development of the origin of the coronary arteries, a matter of ingrowth or outgrowth? Anat Embryol (Berl) 1989;180:437-41. 